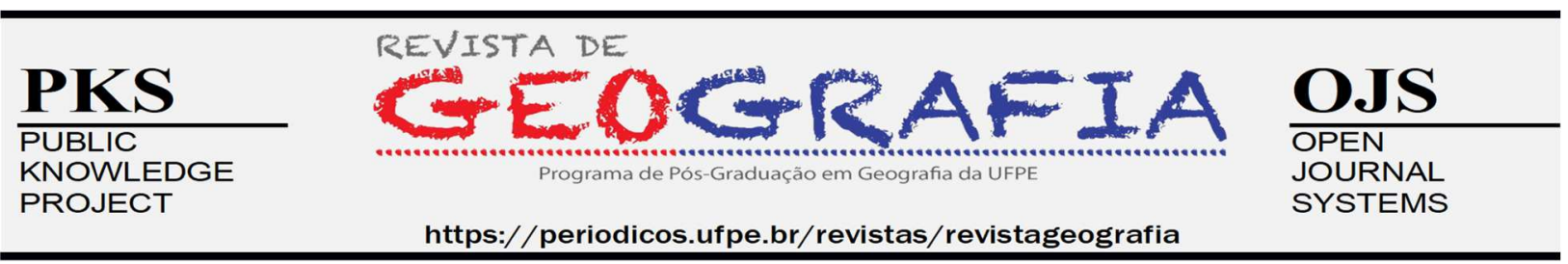

\title{
PARQUE ESTADUAL DA SERRA DOS MONTES ALTOS - BA: HISTÓRICO DE FORMAÇÃO E RECONHECIMENTO DA PAISAGEM
}

\author{
Elaine Moreira de Oliveira ${ }^{1}$, Junívio da Silva Pimentel² \\ ${ }^{1}$ Universidade do Estado da Bahia, E-mail: elaine.cte@ hotmail.com, orcid.org/0000-0003-3326-542X \\ ${ }^{2}$ Universidade do Estado da Bahia, E-mail: juniviopimentel@yahoo.com.br, orcid.org/0000-0001-8401-1409
}

Artigo recebido em 13/08/20 e aceito em 05/03/21

\begin{abstract}
RESUMO
A Serra de Monte Alto localizada no interior da Bahia abrange os municípios: Candiba, Guanambi, Palmas de Monte Alto, Pindaí, Sebastião Laranjeiras e Urandi. Detentora de múltiplas riquezas naturais sua paisagem forma cenário ímpar na região. Com vegetação típica do cerrado circundada por caatinga essa área guarda relevantes patrimônios históricos e naturais. Em função disso, houve necessidade de se criar duas Unidades de Conservação no local, o Parque Estadual da Serra dos Montes Altos e o Refúgio de Vida Silvestre da Serra dos Montes Altos, com intuito de proteger e conservar a biodiversidade ali existente. Com essa perspectiva o presente estudo tem como objetivo compreender histórico de formação do parque, analisando o uso e ocupação do solo antes e após sua criação a partir de levantamento in loco. Para análise e reflexão teórica buscou embasar-se nas concepções de Bahia (2010); Tasso (2012); Pinheiro (2014); INEMA (2019). A criação das Unidades de Conservação trouxeram impactos positivos para biodiversidade regional, formentou a regeneração da vegetação nativa e contribui para coibir possíveis atividades degradantes na área.
\end{abstract}

Palavras-chave: Parque; Serra de Monte Alto; Unidade de Conservação.

\section{THE STATE PARK OF SERRA DOS MONTES ALTOS, BAHIA STATE, BRAZIL: HISTORY OF FORMATION AND LANDSCAPE RECOGNITION}

\begin{abstract}
Serra de Monte Alto, located in the southwestern region of the Bahia State, Brazil, extends over several municipalities: Candiba, Guanambi, Palmas de Monte Alto, Pindaí, Sebastião Laranjeiras and Urandi. It holds multiple natural wealth and a landscape that forms a unique scenario. This area keeps relevant historical and natural heritage with a typical cerrado vegetation surrounded by caatinga. Because of this, two conservation areas were created: The State Park of Serra dos Montes Altos and the Wildlife Refuge of Serra dos Montes Altos, with the purpose of protecting and conserving the biodiversity therein. In this perspective, this paper aims to understand the history of the park's formation, analysing the land use and occupation before and after its creation obtained by the survey "in loco". The theoretical analysis and reflection was based on the following theoretical background: Bahia (2010); Tasso (2012); Pinheiro (2014); INEMA (2019). The creation of conservation areas brought positive impacts to the regional biodiversity, promoted regeneration of native vegetation and contributed to curb possible degrading activities in the area.
\end{abstract}

Keywords: Park. Serra de Monte Alto. Conservation area. 


\section{INTRODUÇÃO}

A Serra de Monte Alto abrange partes dos municípios de Candiba, Pindaí, Guanambi, Sebastião Laranjeiras, Urandi e Palmas de Monte Alto. Possui vegetação característica dos biomas da Caatinga e Cerrado, o que lhe confere diversidade, sendo constatado a presença desde plantas rasteiras à vegetação de médio porte como florestas deciduais e matas de galeria (FILHO, et al. 2012).

Detentora de diversidade biológica, ao longo dos anos foi palco de ações predatórias como exploração madeireira, caça ilegal, atividades de extrativismo desordenado (pecuário e florestal), queimadas e degradação dos solos (INEMA, 2019). Devido a essas e demais circunstâncias houve necessidade de se criar duas unidades de conservação (UC). O Parque Estadual da Serra dos Montes Altos e o Refúgio de Vida Silvestre da Serra dos Montes Altos, criadas pelos decretos estaduais $\mathrm{n}^{\circ}$ 12.486 e 12.487 de 29 de novembro de 2010, visam auxiliar na conservação de biodiversidade e corpos hídricos, além de favorecer o desenvolvimento de atividades socioambientais na área.

O Parque Estadual da Serra dos Montes Altos (PESMA) possui uma área estimada de 18.491 ha e o Refúgio de Vida Silvestre da Serra dos Montes Altos (RVSSMA) 27.499 ha (BAHIA, 2010), contendo dentro e no seu entorno aproximadamente 150 nascentes a exemplo das nascentes dos riachos Mandiroba e Aguapé, a nascente do rio da Casa da Velha ou Curralinho (como é também conhecido), bem como quedas d'água como as cachoeiras da Mandiroba, Brucunum e Buracão (SANCHES e BERNARDES, 2012). Abriga ainda, patrimônio arqueológico, como a "Casa de Pedra" alinhamento de Menires e painéis com inscrições rupestres, poço Azul, Toca dos Tapuios e espécies raras e endêmicas de ecossistemas naturais de transição Caatinga-Cerrado (INEMA, 2019).

Essas caraterísticas fazem com que a área ganhe evidência na paisagem regional. Por outro lado, a riqueza de recursos naturais desperta interesses econômicos que podem culminar em ações que levem prejuízos para a dinâmica ambiental da área, sendo refletido sobre o solo, água, vegetação, fauna, entre outros aspectos.

Para que estas UCs cumpram sua função territorial, faz se necessário esforço conjunto que vai além da sua criação. É imprescindível que haja envolvimento de diversos setores da sociedade e meio ambiente, proporcionando interação e participação dos sujeitos no tocante a questão ambiental. Com essa perspectiva, o presente estudo visa identificar os efeitos obtidos com a criação dessas duas Unidades de Conservação e os desafios para conservação da biodiversidade, com foco nos aspectos vinculados às questões ambientais. Tendo como objetivo compreender o histórico de formação do 
parque, analisando o uso e ocupação do solo antes e após sua criação a partir de levantamento in loco.

Os procedimentos metodológicos, baseou-se em pesquisa de caráter documental, bibliográfico, exploratório, qualitativo com inspeção em campo. Para tanto, a pesquisa bibliográfica e documental fundamentou-se em autores como: BAHIA (2010a, 2010b), Tasso (2012), SANCHES e BERNARDES (2012), MMA (2018), INEMA (2019), entre outros. Para atender a proposta, optouse pelo método geossistêmico, visto que procura englobar os aspectos de maneira integrada. Devido a esse direcionamento, utilizou-se a categoria paisagem.

A pesquisa in loco ocorreu em julho de 2019, realizou-se a entrada no Parque pelo município de Sebastião Laranjeiras (BA) e a saída sentido o município de Candiba (BA). Para isso, houve a colaboração de três guardas do PESMA, os quais, em diálogo anteriormente estabelecido, fizeram a definição dos locais a serem visitados: nascente, cachoeira, sítio arqueológico e áreas degradas.

\section{PARQUE ESTADUAL DA SERRA DOS MONTES ALTOS}

A partir de iniciativas impulsionadas pela ONG Prisma ${ }^{1}$, a biodiversidade existente na Serra de Monte Alto conquistou notoriedade, alcançando apoio de demais entidades em defesa da criação do Parque Estadual da Serra de Montes Altos. Essa mobilização culminou com os decretos de 2010 que constituiu o PESMA e o RVSSMA. As delimitações do Parque e do Refúgio podem ser visualizadas no Mapa 1, no qual fica perceptível que o PESMA se encontra dentro dos limites da área do Refúgio. Em função disso, a área do RVSSMA é 1,5 vezes maior que a área do Parque, contabilizando um total de 18.463,501 ha a mais que o PESMA.

\footnotetext{
${ }^{1}$ Endereço eletrônico: https:// www.serradolagarto.blogspot.com
} 
MAPA 1 - PARQUE ESTADUAL DA SERRA DOS MONTES ALTOS E RVS DA SERRA DOS MONTES ALTOS

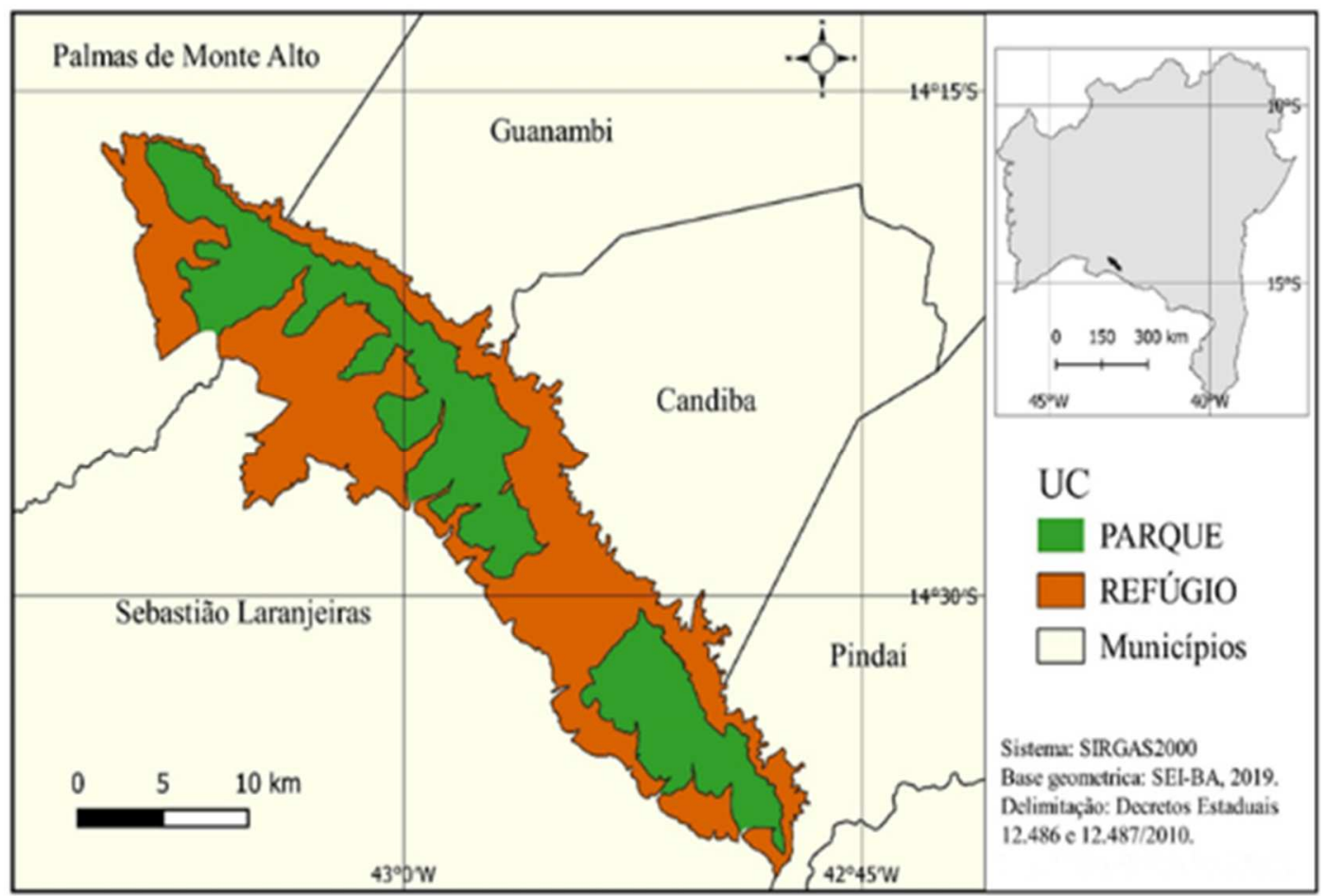

Organização: PIMENTEL, J. Silva, março de 2020.

O Parque abriga dentro e no seu entorno aproximadamente 150 nascentes e diversas cachoeiras a exemplo da Mandiroba (Fotografia 1 A) e Brucunum (Fotografia 1 B).

FOTOGRAFIA 1- CACHOEIRAS NO PESMA
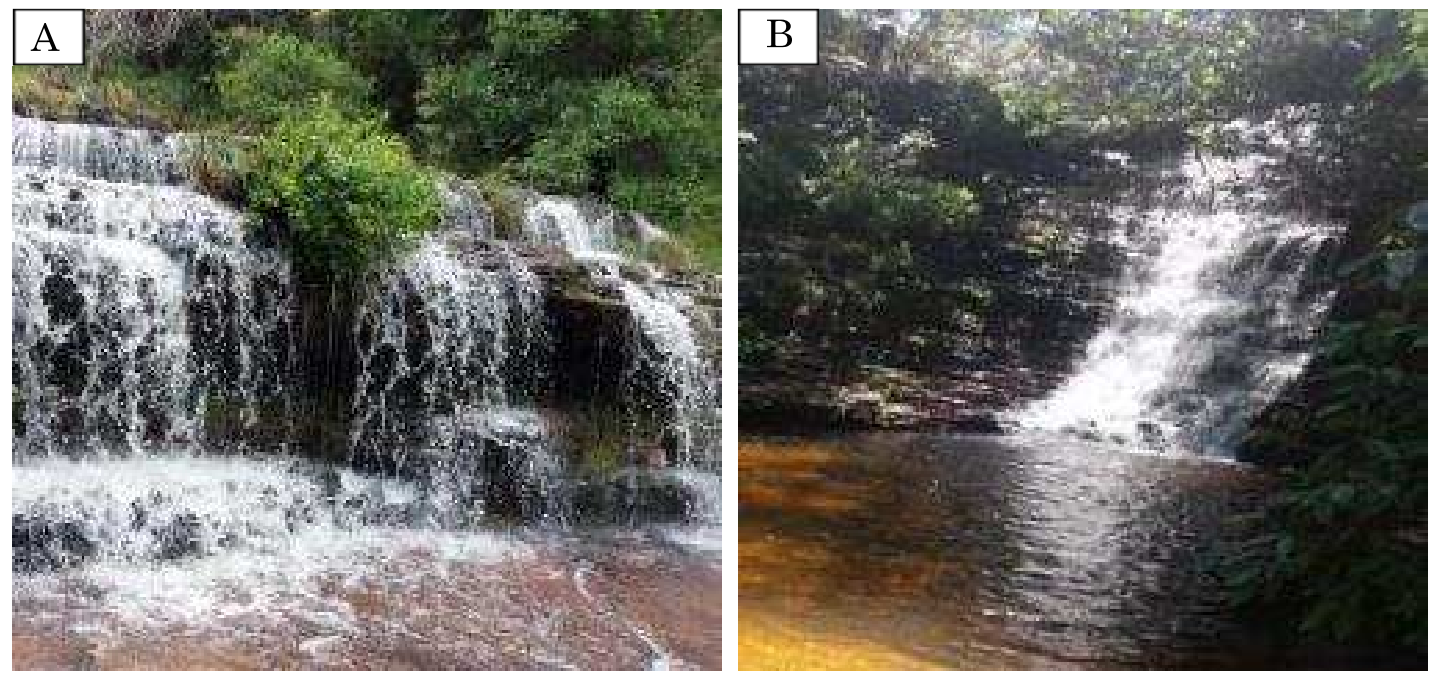

Fonte: Acervo guarda do PESMA, junho/2019. 
Possui patrimônio arqueológicos, a exemplo da "Casa de Pedra" (Fotografia 2) com três cômodos, diversos painéis com inscrições rupestres, sinalizando a existência do homem primitivo nessa região (Fotografia 3), poço Azul, Toca dos Tapuios e espécies raras e endêmicas de ecossistemas naturais de transição Caatinga-Cerrado.

FOTOGRAFIA 2 - CASA DE PEDRA

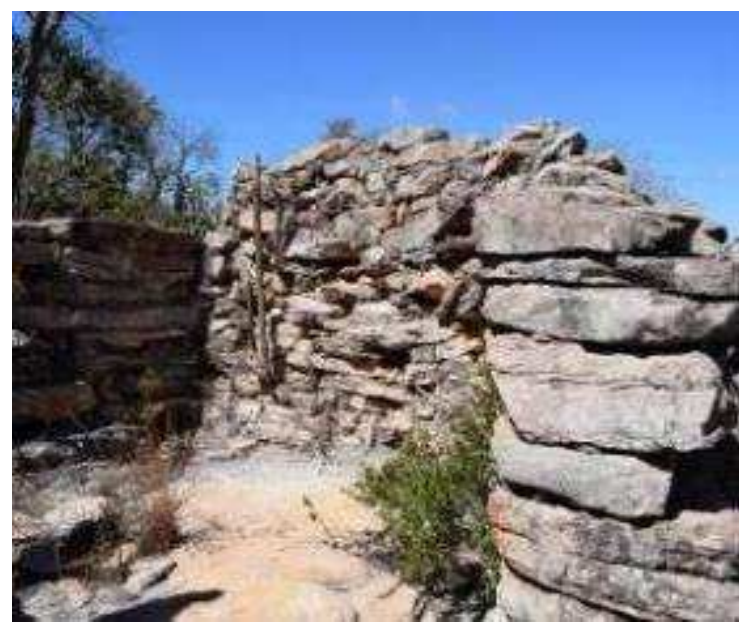

Fonte: ONG Prisma, 2012.

\section{FOTOGRAFIA 3 - INSCRIÇÕES RUPESTRES}

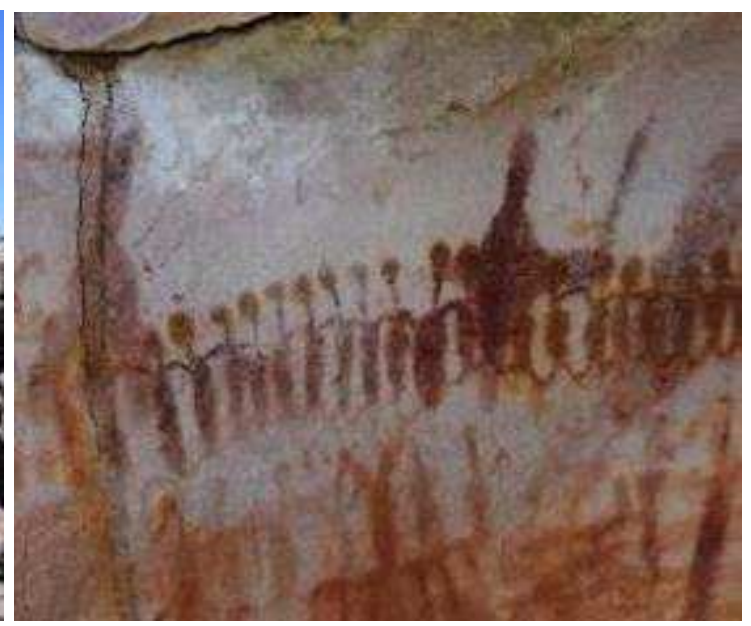

Fonte: ONG Prisma, 2012.

Na Fotografia 4 é possível observar o Alinhamento de Menires $^{2}$ ou "pedra inficada" sítio arqueoastronômico encontrado dentro da área do Parque. De acordo com o guia turístico Reginaldo Azevedo em entrevista concedida ao programa Dendê na Mochila, ao todo existe na área da Serra de Monte Alto aproximadamente 400 blocos de pedras aliadas com a distância de 2 a 3 metros, que caracteriza um calendário solar" (AZEVEDO, s/p. 2017). Ele destaca ainda, que esse tipo de alinhamento de pedras só pode ser encontrado em dois lugares no Brasil, aqui na Bahia na área do PESMA e no Estado do Paraná, Sul do país.

\footnotetext{
${ }^{2}$ Também chamado de perafita, é um grande bloco de pedra, de altura elevada, cravado verticalmente no solo. São considerados monumentos pré-históricos, correspondente ao período Neolítico com finalidades não muito conhecidas, marcos territoriais, orientadores de locais (INFORMAL, 2019, s/p).
} 
FOTOGRAFIA 4 - ALINHAMENTO DE MENIRES

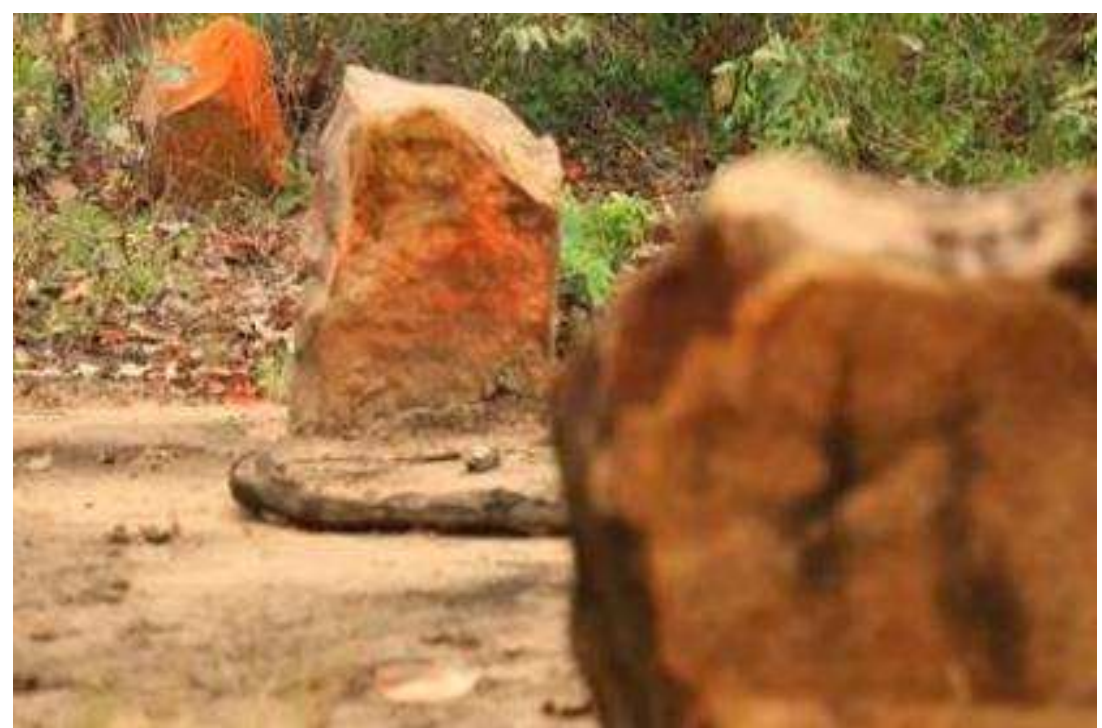

Fonte: Parque Estadual da Serra dos Montes Altos, 2017.

De acordo com os decretos n 12.486 e 12.487, essas duas Unidades de Conservação visam:

I - Assegurar a conservação da biodiversidade regional, garantindo condições para a existência da fauna de mamíferos, com ênfase no cachorro-vinagre, Speothos venaticus, ameaçado de extinção; II - garantir a manutenção de populações viáveis de espécies de mamíferos ameaçadas de extinção, especialmente o cachorro-vinagre, Speothos venaticus; III - proteger integralmente e regenerar os ecossistemas naturais da transição entre Caatinga e Cerrado, por abrigarem espécies raras e endêmicas; IV-proteger o patrimônio arqueológico, emespecial as pinturas rupestres, a estrutura de habitação de pedra denominada 'Casa de Pedra' e o sítio arqueoastronômico; V - manter e recuperar mananciais e cursos d'água; VI - possibilitar o desenvolvimento de atividades de educação e interpretação ambiental e de pesquisa científica (BAHIA, 2010a, 2010b, s/p).

O RVSSMA ainda tem como objetivo, proporcionar conectividade entre as áreas do Parque Estadual da Serra dos Montes Altos, sendo permitido dentro de seus limites assim como no Parque, algumas atividades exploratórias e de manutenção demonstradas nos Quadros 1 e 2.

QUADRO 1 - ATIVIDADES PERMITIDAS NA ZONA DE AMORTECIMENTO E LIMITES DO RVSSMA

\begin{tabular}{|c|c|}
\hline $\begin{array}{l}\text { Atividades permitidas na Zona de } \\
\text { Amortecimento do Refúgio de Vida Silvestre } \\
\text { da Serra dos Montes Altos }\end{array}$ & $\begin{array}{l}\text { Atividades permitidas dentro dos limites do Ref } \\
\text { de Vida Silvestre da Serra dos Montes Altos }\end{array}$ \\
\hline $\begin{array}{l}\text { Atividades minerárias autorizadas pelo } \\
\text { Departamento Nacional de Produção Mineral - } \\
\text { DNPM e licenciadas pelo órgão ambiental } \\
\text { competente até a data de publicação do Decreto } \\
\text { de criação do RVSSMA no } 12.487 / 2010 \text {. }\end{array}$ & $\begin{array}{l}\text { Administração e manutenção da Linha de Distribuição - } \\
\text { LD } 34,5 \mathrm{Kv} \text { - RR, Fazenda Buracão, localizada no trecho } \\
\text { situado dentro dos limites do Refúgio de Vida Silvestre } \\
\text { da Serra de Montes Altos }\end{array}$ \\
\hline
\end{tabular}


Empreendimentos minerários que obtiverem as autorizações, após a publicação do Decreto de criação do RVSSMA $n^{\circ} 12.48$ de 29 de novembro de 2010, respeitadas as disposições do Plano de Manejo da Unidade, quando houver

$\mathrm{O}$ funcionamento das atividades de mineração na Zona de Amortecimento do Refúgio de Vida Silvestre da Serra dos Montes Altos dependerá da plena adequação à legislação de proteção ambiental, às regras específicas estabelecidas pelo órgão responsável pela administração da Unidade de Conservação e ao respectivo Plano de Manejo, submetendo-se ainda à Compensação Ambiental, na forma da lei.

Autorização para construção de imóveis de base residencial ou comercial ficarão a cargo da Prefeitura local, respeitados os critérios e parâmetros definidos no Plano de Manejo.
O traçado da estrada será concebido de acordo com o conceito estabelecido para estrada-Parque, via automotiva que, inserida no todo ou em parte em Unidade de Conservação da natureza, possua características que compatibilizem sua utilização com a preservação dos ecossistemas locais, a valorização da paisagem e dos valores culturais e, ainda, que fomentem a educação ambiental, o turismo consciente, o lazer e o desenvolvimento socioeconômico da região onde está inserida.

Implantação de redes de distribuição de energia elétrica para o atendimento a domicílios rurais situados dentro dos limites do Refúgio de Vida Silvestre da Serra de Montes Altos, desde que licenciadas pelo órgão ambiental competente.

Administração e manutenção da torre de comunicação localizada dentro dos limites do Refúgio de Vida Silvestre da Serra de Montes Altos.

Instalação de redes de abastecimento, esgoto, energia e infraestrutura urbana em geral na Unidade de Conservação dependerá de prévia aprovação do órgão responsável por sua administração, sem prejuízo da necessidade de elaboração de estudos de impactos ambientais e outras exigências legais.

Atividades de criação de animais domésticos, a agricultura familiar e outras formas de utilização da terra, bem como dos recursos naturais compatíveis com os objetivos da Unidade, na forma do que dispuser o Plano de Manejo e demais regulamentos.

Poderão ter continuidade as atividades agropecuárias legalmente autorizadas e/ou consolidadas, consideradas compatíveis com a finalidade da Unidade, desde que adotadas técnicas que minimizem o uso de agrotóxicos e afins.

Autorização para construção de imóveis de base residencial ou comercial fícarão a cargo da Prefeitura local, respeitados os critérios e parâmetros definidos no Plano de Manejo.

Fonte: BAHIA, 2010 b.

Organização: OLIVEIRA, E. M.; PIMENTEL J. Silva., agosto de 2018.

QUADRO 2 - ATIVIDADES PERMITIDAS NAS ZONAS DE AMORTECIMENTO E LIMITES DO PESMA

\begin{tabular}{|c|c|}
\hline 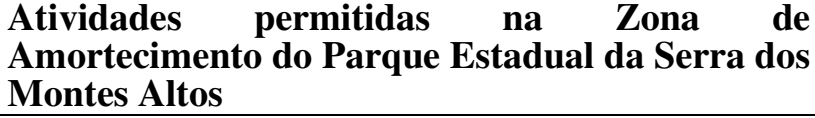 & $\begin{array}{l}\text { Atividades permitidas no Parque Estadual da } \\
\text { Serra dos Montes Altos }\end{array}$ \\
\hline $\begin{array}{l}\text { Atividades minerárias } \\
\text { Departamento Nacional de Produção Madas pelo } \\
\text { Dineral - } \\
\text { DNPM e licenciadas pelo órgão ambiental } \\
\text { competente, até a data de publicação do Decreto de } \\
\text { criacão do PESMA no } 12.486 / 2010 \text {. }\end{array}$ & 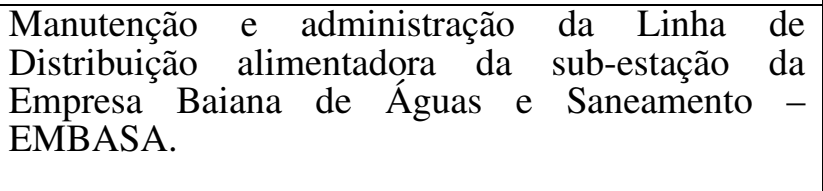 \\
\hline
\end{tabular}




\begin{tabular}{l|l|}
$\begin{array}{l}\text { Empreendimentos minerários que obtiverem as } \\
\text { autorizações, após a publicação do Decreto de de } \\
\text { criação do PESMA no 12.486/2010, respeitadas as } \\
\text { disposições do Plano de Manejo da Unidade, quando } \\
\text { houver. }\end{array}$ & $\begin{array}{l}\text { Instalação de redes de abastecimento, esgoto, } \\
\text { energia e infraestrutura urbana em geral na Unidade } \\
\text { de Conservação dependerão de prévia aprovação do } \\
\text { ógão responsável por sua administraça, sem } \\
\text { prejuízo da necessidade de elaboração de estudos de } \\
\text { impactos ambiental e outras exigências legais. }\end{array}$ \\
\hline $\begin{array}{l}\text { Atividades de mineração na Zona de Amortecimento } \\
\text { do Parque Estadual da Serra dos Montes Altos, de } \\
\text { que trata este artigo, dependerá da plena adequação à } \\
\text { legislação de proteção ambiental, às regras } \\
\text { específicas estabelecidas pelo órgão responsável pela } \\
\text { administração da Unidade de Conservação e ao } \\
\text { respectivo Plano de Manejo, submetendo-se ainda à } \\
\text { Compensação Ambiental, na forma da lei. }\end{array}$ \\
\hline
\end{tabular}

Fonte: BAHIA, 2010 a.

Organização: OLIVEIRA, E. M.; PIMENTEL J. Silva., agosto de 2018.

Essas áreas ao longo do tempo vêm sofrendo com ação antrópica e desenvolvimento de atividades degradantes como produção de carvão vegetal, atividades de extrativismo desordenado (pecuário e florestal), queimadas e degradação dos solos (INEMA, 2019). Logo, criar duas UCs nessa região direcionou à conservação da biodiversidade local, possibilitando a sustentabilidade regional. Contudo, gerenciar e monitorar eventuais infrações nesses espaços de tensão ecológica são desafios a serem enfrentados, pois apesar do esforço da comunidade juntamente com os órgãos competentes, ainda são verificados casos que infringem a exigência legal do Sistema Nacional de Unidades de Conservação da Natureza (SNUC), Lei Federal 9.985/2000 (BRASIL, 2000).

Na tentativa de coibir atividades ilícitas na área do Parque e no seu entorno, o PESMA conta com um total de 12 vigilantes fazendo a proteção e monitoramento do Parque. O monitoramento é realizado diariamente in situ, sendo 2 vigilantes em postos fixos no período diurno e 4 no noturno. Além dos guardas em postos fixos o PESMA conta com uma turma de 6 vigilantes motorizados, percorrendo trajetos pré-estabelecido diariamente, das $8 \mathrm{~h}$ às $18 \mathrm{~h}$. Ressalta-se que se constatado anormalidade o INEMA Posto Avançado de Caetité é imediatamente acionado, dispondo de fiscais para se verificar a denúncia e adotar as medidas cabíveis.

As Unidades de Conservação são criadas pelo poder público em níveis federal, estadual e municipal, a partir de estudos técnicos e consulta pública, a qual permite que a sociedade participe do processo, oferecendo subsídios para o aprimoramento da proposta (MMA, 2018). De acordo com a legislação atual, pode-se afirmar que em todas as categorias de Unidade de Conservação são aceitas atividades que estimulem o conhecimento científico e ambiental, além de favorecer a criação de cadeias produtivas de diversos bens e serviços, propiciando surgimento de pólos de desenvolvimento 
sustentável e contribuindo para melhoria na qualidade de vida da população.

Segundo informações do Cadastro Nacional de Unidades de Conservação citado por Pinheiro (2014) há no Estado da Bahia 165 Unidades de Conservação divididas em dois grupos específicos, as de Proteção Integral e de Uso Sustentável. No que concerne à categoria de Uso Sustentável a Bahia possui 137 UCs neste grupo de proteção, com uma área estimada de 55.450,07 $\mathrm{km}^{2}$ no total. As UCs classificadas como Uso de Proteção Integral contabilizam 28, dentre essas se destacam os parques, totalizando 14 entre as 28 UCs dessa categoria, formando uma área no total de $225.698,47 \mathrm{~km}^{2}$.

Dos 14 parques baianos apenas três possuem Plano de Manejo (PM), são eles: Parque Estadual da Serra do Conduru, Parque Nacional da Chapada Diamantina e o Parque Nacional Marinho dos Abrolhos. Enquanto os demais parques ${ }^{3}$ encontram-se sem PM. Três desses Parques são de gestão administrativa estadual, entre eles está o Parque Estadual das Serra do Montes Altos, administrado pela Secretaria do Meio Ambiente (SEMA), por meio de sua autarquia Instituto do Meio Ambiente e Recursos Hídricos (INEMA), através da Diretoria de Unidades de Conservação (DIRUC).

Para que as UCs cumpram com o papel para o qual foram criadas, é fundamental o envolvimento de diversos setores da sociedade, proporcionando, interação e participação dos indivíduos no tocante a questão ambiental. Nesse sentido, torna-se imprescindível que as UCs possuam seu respectivo PM, além da formação de Conselhos Gestores.

Segundo a Lei $n^{\circ} 9.985$ que criou o Sistema Nacional de Unidades de Conservação da Natureza (SNUC), citada pelo MMA (2002, p. 16) o Plano de Manejo constitui:

Documento técnico mediante o qual, com fundamento nos objetivos gerais de uma Unidade de Conservação, se estabelece o seu zoneamento e as normas que devem presidir o uso da área e o manejo dos recursos naturais, inclusive a implantação das estruturas físicas necessárias à gestão da Unidade.

O PM juntamente com o Conselho gestor auxiliam no planejamento e gestão das UCs, além de direcionar regulamentos e objetivos conforme os princípios e diretrizes do SNUC. De acordo com o Ministério do Meio Ambiente cada UC deve ter seu próprio Conselho Gestor que tem como função principal "auxiliar o chefe da UC na sua gestão, e integrá-la à população e às ações realizadas em seu entorno" (MMA, 2019, s/p). As categorias de Unidade de Conservação poderão ter, conforme a Lei

\footnotetext{
${ }^{3}$ Parque Estadual do Morro do Chapéu, Parque Estadual das Setes Passagens, Parque Estadual da Serra dos Montes Altos, Parque Nacional das Nascentes do Rio Parnaíba, Parque Nacional do Descobrimento, Parque Nacional Pau Brasil, Parque Nacional do Monte Pascoal, Parque Nacional de Boa Nova, Parque Nacional da Serra das Lontras, Parque Nacional do Alto Cariri e o Parque Nacional do Boqueirão da Onça.
} 
$\mathrm{n}^{\circ}$ 9.985/2000 “conselho consultivo ou deliberativo, que serão presididos pelo chefe da Unidade de Conservação, o qual designará os demais conselheiros indicados pelos setores a serem representados" (MMA, 2011, p. 40).

As categorias de UC com Conselho Consultivo são: Parque Nacional, Reserva Biológica, Estação Ecológica, Monumento Natural, Refúgio de Vida Silvestre e Florestas Nacionais. Já as Reservas Extrativistas e as Reservas de Desenvolvimento Sustentável se enquadram nas Categorias de UC com Conselho Deliberativo-

Com relação ao Parque PESMA e RVSSMA a Sema et al. (2015) afirmam que os mesmos, possuem Conselho Gestor inativo e encontra-se atualmente sem Plano de Manejo. No entanto, segundo Bahia (2018) no final do ano de 2018 o governo da Bahia iniciou processo seletivo com edital $n^{\circ}$ 001/2018 para celebrar acordo de cooperação, com objetivo de eleger entidade de direito privado sem fins lucrativos para elaboração do Plano de Manejo do PESMA e do RVSSMA. A organização selecionada terá o prazo de 18 meses para conclusão do Plano de Manejo. Portanto, o PM encontra-se em fase de elaboração, sendo coordenado pelo Instituto do Meio Ambiente e Recursos Hídricos da Bahia (INEMA).

\section{VISITA TÉCNICA À AREA EM ESTUDO}

Apesar de ter se passado quase dez anos da criação do PESMA e RVSSMA, durante visita técnica foi possível notar marcas da interferências humana nessas UCs, entre elas se destacam as áreas que sofreram com a retirada da vegetação nativa para práticas agropecuárias e mineradoras, (Fotografias 5 A, B, C e D). 


\section{FOTOGRAFIA 5 - ÁREAS ALTERADAS POR ATIVIDADES AGROPECUÁRIAS E MINERADORAS}
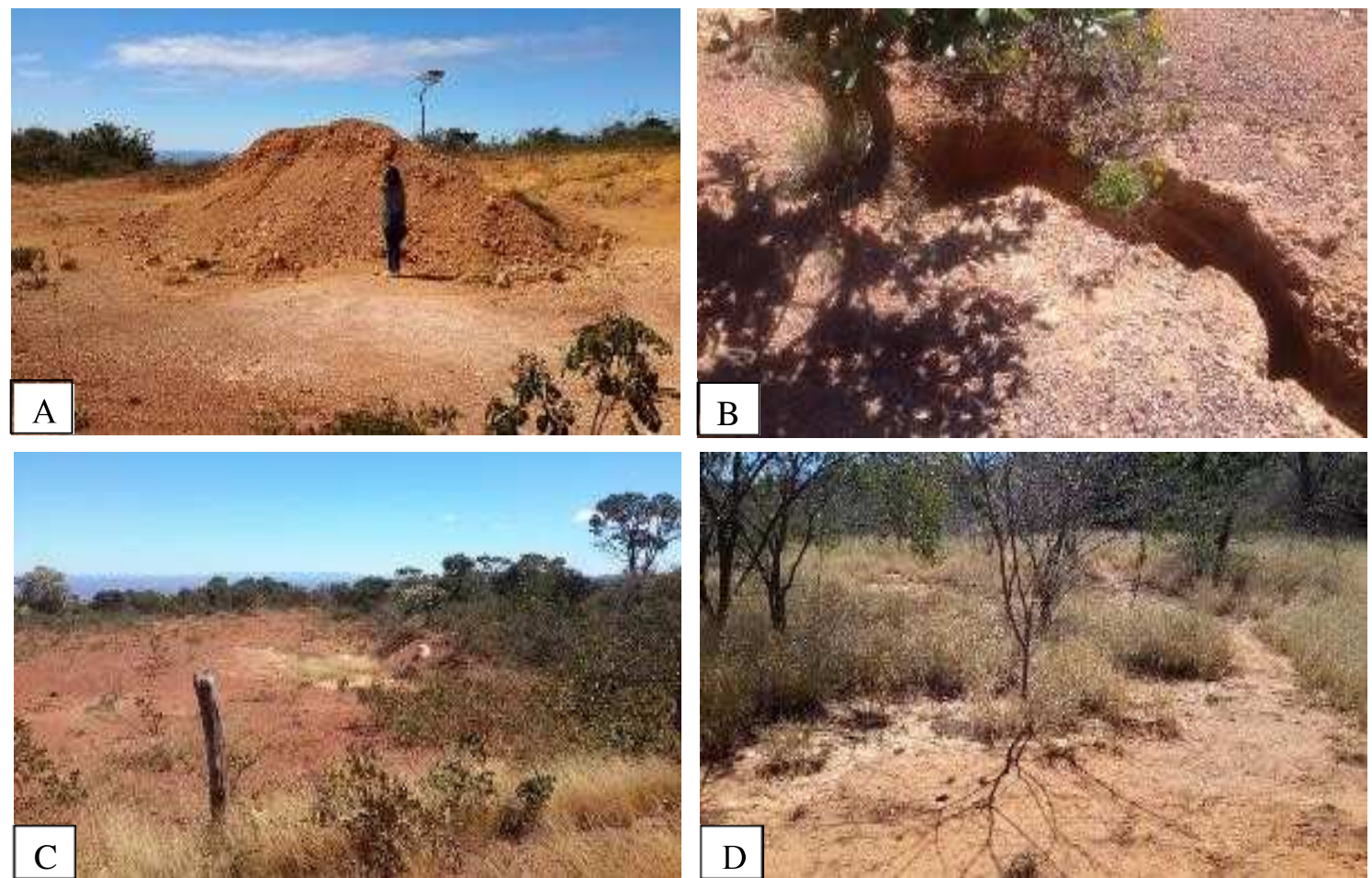

Fonte: Visita de campo, julho de 2019.

Nos locais onde ocorriam atividades mineradoras de extração de cascalho (Fotografia A) é possível verificar a retirada da cobertura vegetal, solo exposto e ações dos intemperismos, com sinais de erosão pluvial do tipo sulcos e ravinas (Fotografia 5 B). Por conta do relevo acidentado, a área está susceptível aos processos erosivos. No entanto, apesar da existência dessas atividades no Parque, o que se observa nos locais visitados são alterações pontuais causando menos alterações ambiental, por não localizarem próximo de nascentes.

Pela inspeção visual da paisagem a cobertura vegetal do PESMA e RVSSMA encontra-se em processo de regeneração. É possível perceber que o solo, que outrora fora desmatado para cultivo do capim está sendo recoberto pela vegetação nativa (Fotografia $5 \mathrm{C}$ e D). Segundo relatos dos guardas, era comum nessas areas do Parque a prática de criação de gado pelos moradores circunvizinhos, haja vista, a disponibilidade de alimentos e fontes de água. Essa atividade, embora se encontra em áreas isoladas do PESMA, ainda não foi erradicada devido à ausência do Plano de Manejo. Assim como a desapropriação de imóveis rurais existentes nos limites descritos no Art. $1^{\circ}$ do Decreto no 12.486 de criação do PESMA (BAHIA, 2010a) e a nulidade de eventuais títulos de propriedade e respectivos registros imobiliários considerados irregulares. Todavia, durante visita 
técnica, verificou-se existência de residência abandonada (Fotografia $6 \mathrm{~A}$ e B) próxima à nascente da cachoeira do Buracão (Fotografia 6 C e D).

\section{FOTOGRAFIA 6 - IMÓVEL LOCALIZADO NAS PROXIMIDADES DA CACHOEIRA DO BURACÃO}
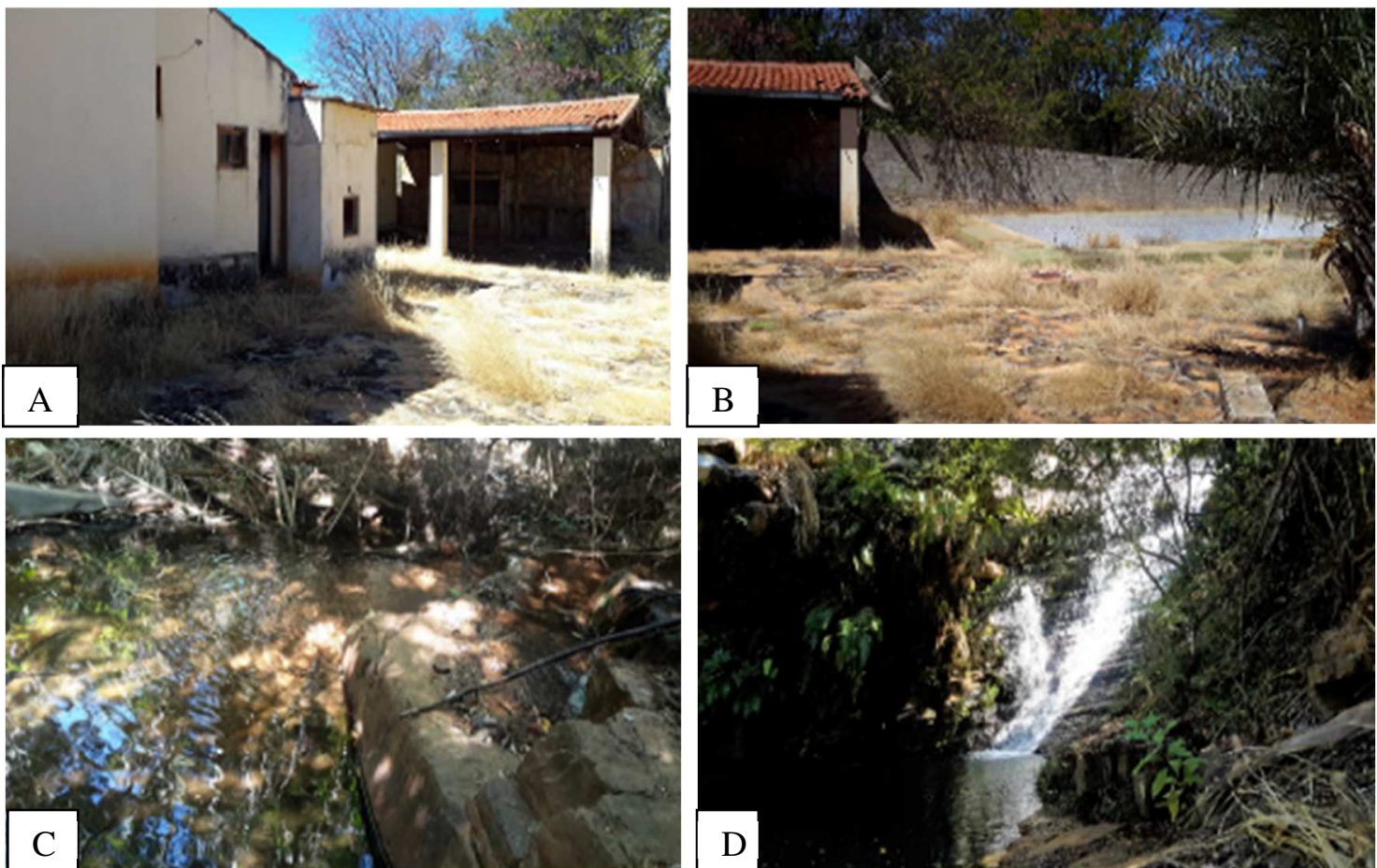

Fonte: Visita de campo, julho de 2019.

Os guardas relataram que o proprietário costumava utilizá-la para veraneio e, com a criação do Parque deixou de frequentá-la por iniciativa própria. De acordo com BAHIA (2010a), a Secretária da Administração (SAEB) e a Secretária do Meio Ambiente (SEMA) estão autorizadas a adotar medidas cabíveis no sentido de avaliar e incorporar ao patrimônio do Estado os imóveis a serem desapropriados dentro do Parque. No entanto, segundo técnico do INEMA, órgão responsável pela gestão do PESMA, essas ações dependem do Plano de Manejo para serem executadas. O que poderá acontecer em um futuro próximo, já que o PM se encontra em fase de elaboração. Atualmente, está a cargo do INEMA proteção, manutenção e controle, visando coibir atividades ilegais nas UCs.

A nascente da cachoeira do Buracão (Fotografia 6 C) está localizada numa área elevada, logo abaixo encontra-se a queda d'água que dá vida a cachoeira (Fotografia 6 D). O caminho para se chegar a esse local é íngreme e de difícil acesso, no entanto, ao fim da caminhada o visitante/pesquisador se depara com cascata de água transparente, cercada por rochas e vegetação do 
tipo Caatinga.

De acordo com os guardas, é comum aos fins de semana, moradores próximos e visitantes de cidades circunvizinhas adentrarem ao Parque para desfrutar desse ambiente. Além da cachoeira do Buracão existe no Parque mais duas quedas-d'água que formam, a cachoeira da Mandiroba e do Brucunum. Devido à localização e facilidade no acesso, as duas últimas são mais visitadas. Os guardas expressaram certa preocupação, com relação ao fluxo de visitantes não autorizados, devido à quantidade de lixo que deixam espalhados. É comum encontrarem pelo caminho de acesso e em volta das quedas d'água embalagens plásticas e garrafas pet.

Além das cachoeiras, painéis com figuras rupestres (Fotografia 8) e paisagens de beleza cênica, o Parque Estadual da Serra dos Montes Altos, também "abriga um importante sistema de águas superficiais que recarrega rios e aquíferos, esses por sua vez, abastecem ecossistemas de brejos temporários, lagos, lagoas artificiais e naturais, bem como municípios e povoados do seu entorno" (TASSO, 2012, p. 107).

A abundância do recurso água observada em aquíferos na área em estudo tem influência direta da composição da sua geologia. Sendo constituída por rochas de natureza sedimentar, torna favorável que a água subterrânea transpasse pelos poros da rocha, desencadeando no aparecimento de aquíferos. O clima, por sua vez, varia devido às características altimétricas, tornando-se mais ameno e chuvoso na cimeira da Serra. Esses índices pluviométricos, assim como o relevo, influem nas características dos cursos d'água, o que pode ser visto no seu fluxo e vazão. Devido a esses aspectos do clima o intemperismo químico é intenso e, deste modo, influência nas características do solo. A composição dos solos em conjunto com o relevo e clima influem na composição da vegetação.

As figuras rupestres, que atraem a atenção de visitantes e pesquisadores, estão presentes em dois pontos do Parque, estando um painel situado em uma localidade pertencente ao município de Candiba-BA (Fotografia 7) por ter melhor acesso e as figuras estarem mais nítidas, este local contabiliza maior número de visitantes. 


\section{FOTOGRAFIA 7 - PAINEL DE FIGURAS RUPESTRES NO PESMA, MUNICÍPIO DE CANDIBA-BA}
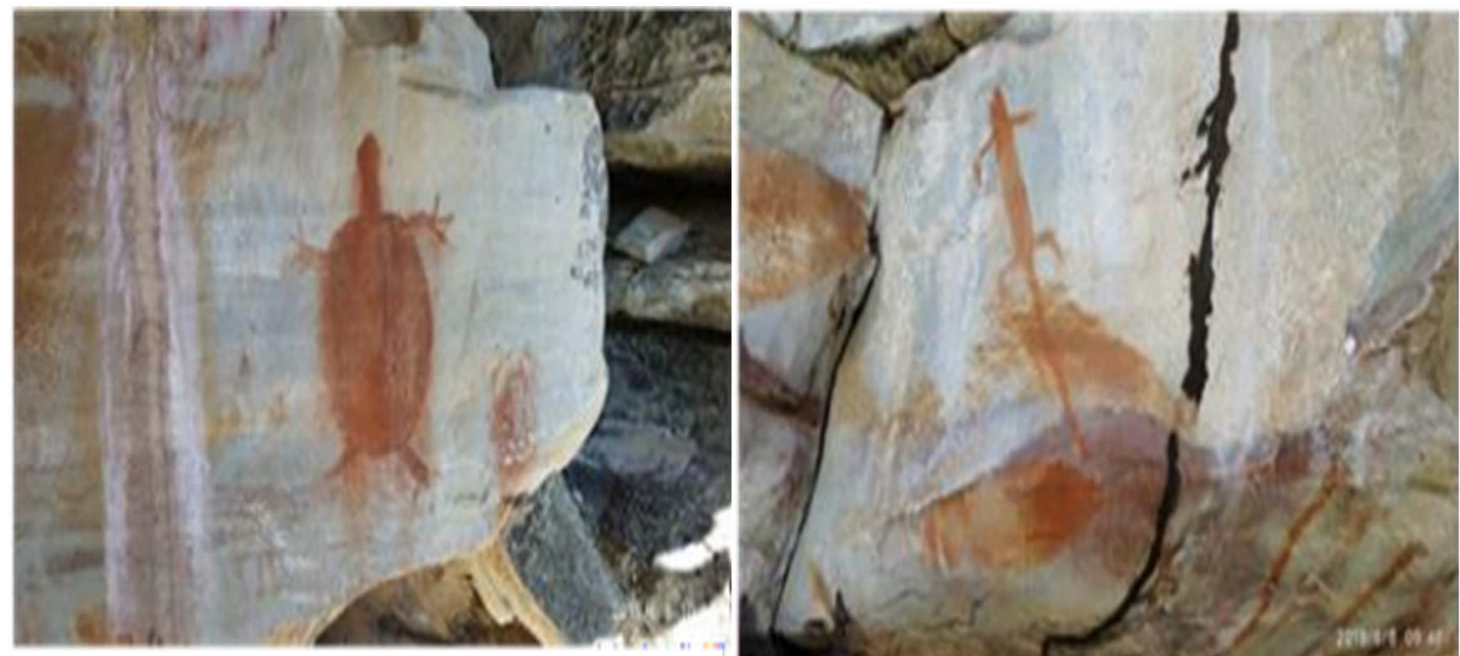

Fonte: Acervo guarda do PESMA, junho 2019.

O segundo painel se encontra numa área do Parque entre os municípios de Sebastião Laranjeiras e Palmas de Monte Alto (fotografia 8 A, B) numa zona de mata fechada e difícil acesso.

\section{FOTOGRAFIA 8 - PAINÉIS DE FIGURAS RUPESTRES NO PESMA}
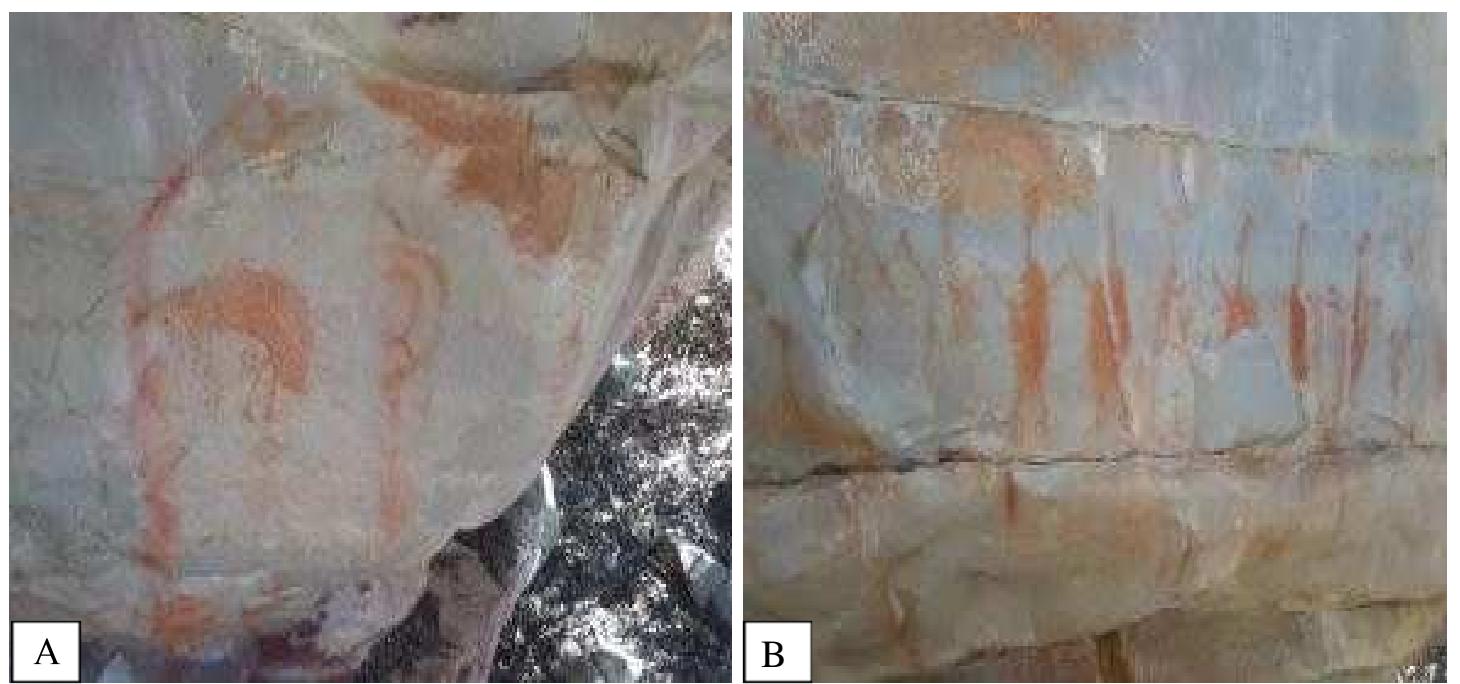

Fonte: Visita de campo, julho de 2019.

Na Fotografia 8 A é possível identificar uma figura que se assemelha a forma de um animal, representando, rota de caça ou ritual religioso. Já na Fotografia $8 \mathrm{~B}$, de acordo com os guardas, historiadores que visitaram o Parque afirmaram se tratar da representação de uma família. Não é possível afirmar ao certo se são de fato representações de pessoas ou animais, o que se sabe é que são registros históricos que confirmam a presença do homem primitivo na região. Como é possível 
perceber pelas Fotografias 8 (A e B) devido aos intemperismos físicos, os desenhos sofreram desgastes dificultando sua visualização, mas não perderam sua relevância, pois as artes rupestres são essenciais para entendimento das sociedades primitivas e ocupações territoriais, que antes mesmo da escrita já registravam cenas do seu cotidiano por meio de pinturas.

A visita ao PESMA e RVSSMA possibilitou constatar que a criação dessas duas UCs vem contribuído de forma significativa para a conservação e preservação do patrimônio histórico e ambiental da Serra de Monte Alto. Segundo os guardas do Parque, atualmente o principal alvo de suas ações, são coibir as atividades de caça ilegal que representa risco a integridade da biodiversidade da fauna local.

\section{CONSIDERAÇÕES FINAIS}

Com o estudo verificou-se que a criação do PESMA e RVSSMA teve impacto positivo para biodiversidade regional. A área que abrange a Serra de Palmas de Monte Alto, atual área do Parque, passou a ser protegida contribuindo para conservação e preservação de seu patrimônio natural e histórico. É fato que existem algumas práticas degradantes que ainda não foram totalmente erradicadas como agropecuária e extração mineral no local. No entanto, essas atividades passaram a ser monitoradas por fiscais do INEMA, o que impede alterações mais incisivas e/ou expansão da área. A existência dessas atividades em determinados pontos do Parque gera um certo desconforto, no sentido de vir de encontro com os objetivos do PESMA (BAHIA, 2010).

Questões como essas, sem dúvida serão abordadas no Plano de Manejo que em breve deverá ser concluído. Em resumo acredita-se que a demora na execução do PM, que segundo o Ministério do Meio Ambiente deve ser elaborado no prazo máximo de 5 anos após a criação da Unidade de Conservação, vem contribuindo para alterações negativas na conservação da biodiversidade da área, decorrentes de atividades que vem se estendendo após a criação do Parque. Tendo em vista que a eficácia das UCs não depende exclusivamente de sua criação, incluem também, ações e atividades necessárias como: proteção, recreação, educação ambiental, pesquisa e manejo dos recursos e interrelações mantidas com as comunidades adjacentes, para que sua criação seja de fato efetiva e não produza apenas "parques de papel”.

Em contrapartida, compreende-se que as Unidades de Conservação não são espaços intocáveis. Portanto, podem e devem ser vistas como uma maneira especial de ordenamento territorial 
e não como um entrave ao desenvolvimento econômico e, socioambiental (GURGEL et al, 2009). Dessa forma, se desenvolvidas em bases sustentáveis e em consonância com as diretrizes do Plano de Manejo (elaborado em função dos objetivos gerais pelos quais ela foi criada), as atividades que envolvem coleta e uso dos recursos naturais poderá gerar renda, emprego e crescimento econômico, beneficiando a população local.

\section{REFERÊNCIAS}

AZEVEDO, R. Parque Estadual da Serra dos Montes Altos. Direção: Matheus Boa Sorte. Produção: Carrollini Assis e Emerson Manoel. Apresentador: Matheus Boa Sorte. Episódio 063, $3^{\mathrm{a}}$ temporada. [s. l.]: TV Aratu/SBT Bahia, 17 abr. 2017. 1 vídeo (50 min). Publicado pelo canal Dendê na Mochila. Disponível em: https://www.youtube.com/watch?v=e6gb5yuYtfA. Acesso em: 12 jul. 2018.

BAHIA. Decreto n⿳ 12.486 de 29 de novembro de 2010. Cria o Parque Estadual da Serra dos Montes Altos, no Estado da Bahia, e dá outras providências. Salvador, BA, Palácio do Governo do Estado da Bahia, 29 de novembro de 2010a. Disponível em: http://www.oads.org.br/leis/2748.pdf. Acesso em: 4 nov. 2018

. Decreto no 12.487 de 29 de novembro de 2010. Cria o Refúgio de Vida Silvestre da Serra dos Montes Altos, no Estado da Bahia, e dá outras providências. Salvador, BA, Palácio do Governo do Estado da Bahia, 29 de novembro de 2010b. Disponível em: http://oads.org.br/leis/2749.pdf. Acesso em: 4 nov. 2018.

Edital de Chamamento Público no 001/2018 acordos de cooperação. Seleção de organização da sociedade civil sem fins lucrativos interessada em celebrar Acordo de Cooperação cujo objeto é a execução de atividades decorrentes da Compensação Ambiental em sua modalidade indireta. Salvador, BA: Secretaria do Meio Ambiente - SEMA, Processo Administrativo $\mathrm{n}^{\circ}$ 1420170008670, dez. 2018.

Conferência Territorial de Cultura: Sertão Produtivo. 2013. Disponível em: https://conferenciadecultura.files.wordpress.com/2013/07/cartilha_sertao_produtivoweb.pdf. Acesso em: 1 mai. 2020.

BRASIL. LEI no 9.985, de 18 de julho de 2000. Regulamenta o art. 225, § 1o, incisos I, II, III e VII da Constituição Federal, institui o Sistema Nacional de Unidades de Conservação da Natureza e dá outras providências. Disponível em: < http://www.planalto.gov.br/ccivil_03/leis/19985.htm>. Acesso em: 5 dez. 2018.

FILHO, A. de O. S.; HARLEY, A. M. G.; SOUZA, A. de O. Conservação do Parque e Refúgio da Serra dos Montes Altos. In: SILVA, Joaquim Perfeito da (org.). Territórios e ambientes da Serra de Monte Alto: Região Sudoeste da Bahia. Vitória da Conquista, BA: Edições UESB, 2012.

GURGEL, H. C.; HARGRAVE, J.; FRANÇA, F.; HOLMES, R. M.; RICARTE, F. M.; DIAS, B. F. S.; RODRIGUES, C. G. O.; BRITO, M. C. W. Unidades de conservação e o falso dilema entre conservação e desenvolvimento. Boletim Regional, Urbano e Ambiental, [Brasília, DF]: IPEIA, n. 3, p. 109 - 119, dez. 2009. 
ICMBIO. Instituto Chico Mendes de Conservação da Biodiversidade. Conselhos. Brasília, DF, 2019. Disponível em: http:// www.icmbio.gov.br/portal/unidadesdeconservacao/conselhos. Acesso em: 19 jan. 2019.

INEMA. Instituto do Meio Ambiente e Recursos Hídricos. Parque Estadual da Serra dos Montes Altos. Salvador, BA, 2019. Disponível em: http://www.inema.ba.gov.br/parque-estadual-da-serrados-montes-altos/. Acesso em: 23 abr. 2019.

INFORMAL. Dicionário. Menir. $2019 . \quad$ Disponível em: https://www.dicionarioinformal.com.br/menir/. Acesso em 07 out. 2019.

MMA. Ministério do Meio Ambiente. Roteiro metodológico de planejamento: Parque nacional, Reserva Biológica, Estação Ecológica. [S. l.]: Edições IBAMA, 2002.

Ministério do Meio Ambiente. SNUC - Sistema Nacional de Unidades de Conservação da Natureza: Lei $n^{\circ}$ 9.985, de 18 de julho de 2000; Decreto $\mathrm{n}^{\circ}$ 4.340, de 22 de agosto de 2002; Decreto $\mathrm{n}^{\mathrm{o}}$ 5.746, de 5 de abril de 2006. Plano Estratégico Nacional de Áreas Protegidas: Decreto nº5.758, de 13 de abril de 2006. Brasília, DF: MMA/SBF, 2011.

Ministério do Meio Ambiente. Unidades de Conservação. Brasília, DF, 2018. Disponível em: http://www.mma.gov.br/areas-protegidas/unidades-de-conservacao/criacao-ucs.html. Acesso em: 10 dez. 2018.

Ministério do Meio Ambiente. Conselhos Gestores. Brasília, DF, 2019. Disponível em: http://www.mma.gov.br/areas-protegidas/unidades-de-conservacao/conselhos-gestores.html. Acesso em: 17 abr. 2019.

PINHEIRO, C. M. de. Gestão da biodiversidade na Bahia: Avanços e desafios nos parques nacionais e estaduais. 2014. Dissertação (Pós-Graduação em Gestão Florestal) - Universidade Federal do Paraná, Curitiba, Paraná, 2014.

SANCHES, A. L.; BERNARDES, Eduardo Silveira. Aspectos geológicos preliminares da unidade de conservação da Serra de Monte Alto. In: SILVA, Joaquim Perfeito da (org.). Territórios e ambientes da Serra de Monte Alto: Região Sudoeste da Bahia. Vitória da Conquista, BA: Edições UESB, 2012.

SEMA; INEMA; DIRUC. CONTRATAÇÃO DE SERVIÇOS TÉCNICOS ESPECIALIZADOS (PESSOA JURÍDICA) PARA PROMOVER A REGULARIZAÇÃO AMBIENTAL DE IMÓVEIS RURAIS NO ENTORNO DOS PARQUES ESTADUAIS PESC, PESMA, PEMC E PESP NO ÂMBITO DO CADASTRO NO CEFIR (CADASTRO ESTADUAL FLORESTAL DE IMÓVEIS RURAIS). Salvador, $\quad 2015 . \quad$ BA, Disponível em: http://www.meioambiente.ba.gov.br/arquivos/File/CCA/TRCEFIR.pdf. Acesso em: 10 jan. 2019.

TASSO, M. A. de L. Caracterização dos sedimentos superficiais e avaliação ambiental da Serra de Monte Alto entre os municípios de Palmas de Monte Alto e Sebastião Laranjeiras, BA. 2012. Tese (Doutorado em Geociências e Meio Ambiente) - Universidade Estadual Paulista, Rio Claro, SP: [s.n.], 2012. 